\title{
SYNTHESIS OF ZNO/CNTS NANOCOMPOSITE THIN FILM AND ITS SENSING
}

\author{
Rakesh K. Sonker, B.C. Yadav \\ Dept. of Applied Physics, Babasaheb Bhimrao Ambedkar University, Lucknow-226025, \\ Email: balchandra_yadav@rediffmail.com,
}

\begin{abstract}
Semiconductor metal oxides (SMOs) with nanostructures as gas sensing material have been widely used in detection of toxic gases and vapours. The gas sensing properties of the SMO-based sensors are highly dependent not only on their surface chemical reactivity and thermal stability but also on the geometrical and compositional variation. Nitrogen dioxide $\left(\mathrm{NO}_{2}\right)$ is a typical air pollutant that causes environmental problems. The exact detection of ultra-low concentrations of $\mathrm{NO}_{2}$ is becoming very important now days. In order to enhance the sensitivity of carbon nanotube based chemical sensors at room temperature operation, SWCNTs/ZnO nanocomposite was prepared under chemical reaction condition. The layer of deposition was applied for the spin coating of the inner and outer SWCNTs walls with thin films of $\mathrm{ZnO}$ of precisely controlled thicknesses. Differently treated SWCNTs with different degree of surface functionalization were used as support for the oxide films. The sensing properties of the obtained composite materials towards $\mathrm{NO}_{2}$ were investigated and related to the morphological and microstructural characteristics of both the coating and support. ZnO-based composites on SWCNTs treated at $300{ }^{\circ} \mathrm{C}$ show enhanced performance as sensors, making them suitable for practical applications. Sensor structure showed a better sensing response $\left(S \sim 1.51 \times 10^{2}\right)$ at operating room temperature towards $20 \mathrm{ppm} \mathrm{NO}$ gas with an average response times of about $2.45 \mathrm{~min}$.
\end{abstract}

\section{INTRODUCTION}

High surface area composite hetero-structures based on zinc oxide and carbon nanotubes (CNTs) exhibit unique electrical properties that are related to the presence of a p-n hetero-junction. Their electric conductivity can be influenced by the surrounding atmosphere. Therefore, these structures present a substantial potential as new gas sensing materials [1]. In order to study these hetero-systems, thin films of $\mathrm{ZnO}$ have been deposited by atomic layer of surface, a surface-gas phase process based on sequential, selflimiting surface reactions. A fine control of the morphology and thickness of the deposited films can be achieved by this technique [2]. In view of gas sensors applications, great interest is devoted on $\mathrm{SnO}_{2}, \mathrm{TiO}_{2}, \mathrm{ZnO}$ semiconductor layers with a thickness in the order of the Debye length [3-5]. Previously it was shown that the tailoring of the type and degree of functionalization of the CNTs surface allows to tune the $\mathrm{ZnO}$ coating from selectively decorated up to fully coated CNTs [6]. Tessonnier et al. demonstrated that the carbon nanotubes surface graphitic character influences the type and density of surface groups created during functionalization by nitric acid treatment [7]. Commercial
CNTs with different degree of graphitization, prepared by different thermal treatments prior to a standard acid treatment, were used as carbon support [2]. The gas sensing properties of the obtained hetero-structures towards $\mathrm{NO}_{2}$ were investigated.

\section{EXPERIMENTAL}

$0.01 \mathrm{M}$ of zinc acetate dihydrate was dissolved in 75 $\mathrm{ml}$ of boiling ethanol $\left(150^{\circ} \mathrm{C}\right)$ in a round bottom flask fitted with a condenser at atmospheric pressure. The solution is refluxed at $75^{\circ} \mathrm{C}$ for about 30 minutes and subsequently allowed to cool at room temperature to give a transparent and stable $\mathrm{Zn}$ based precursor. In another beaker, $0.014 \mathrm{M}$ of lithium hydroxide monohydrate was ultrasonically dissolved in $50 \mathrm{ml}$ of ethanol to accelerate the reaction at room temperature. A clear solution was obtained after sonication for $60 \mathrm{~min}$. The hydroxide containing solution was added drop by drop to the acetate containing solution at room temperature under vigorous magnetic stirring, and finally a transparent $\mathrm{ZnO}$ sol was obtained after hydrolyzing the precursor [8]. The ZnO- SWCNT thin films were obtained by mixing different concentrations ( $1 \mathrm{mg}, 3 \mathrm{mg}$, and $5 \mathrm{mg}$ ) of SWCNTs in the as prepared tin compound solution and were stirred overnight under closed conditions before use. Thin films 
of hybrid SWCNT-ZnO nanoparticles with a thickness of about $500 \mathrm{~nm}$ were deposited on the Corning glass substrate using a spin coating technique and exposed to thermal treatment at $150^{\circ} \mathrm{C}$ for 5 min after every coating to evaporate the organic precursors. Finally, the thin films of desired thickness were annealed in air at $300^{\circ} \mathrm{C}$ for 1 $\mathrm{h}$ to obtain the appropriate crystallinity. However, prior to deposition of sensing SWCNT-ZnO nanoparticles films, inter digital electrodes (IDEs) of platinum (Pt) were patterned on the cleaned surface of the corning glass substrate using conventional photolithography techniques. Fig. 1 is shows the schematic diagram of the sensor structure.

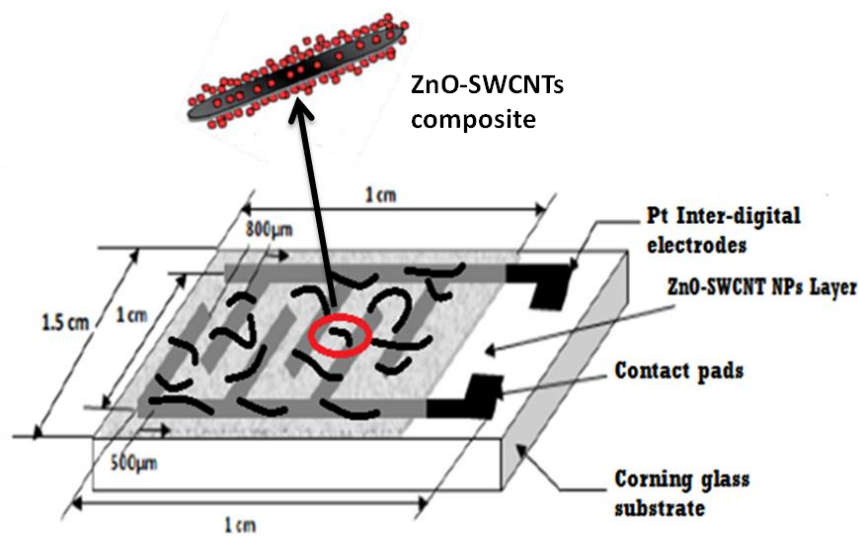

Fig. 1: Schematic diagram of ZnO-SWCNT thin film sensor structure

\section{A. Experimental Techniques}

Thickness and surface roughness of the deposited thin films were measured using a Veeco Dektak 150 surface profiler. Surface morphologies were investigated using scanning electron microscope (SEM) and atomic force microscopy (Veeco DICP2), respectively. A Fourier transform infrared spectroscopy (Thermo Scientific, USA, Nicolet ${ }^{\mathrm{TM}}$ 6700) was used to study the optical properties of $\mathrm{ZnO}$ and $\mathrm{ZnO}$-SWCNT thin films. For studying the gas sensing properties, gas dilution system developed by our group was utilized [9]. Two platinum electrodes were grown on $\mathrm{ZnO}$ thin film and $\mathrm{NO}_{2}$ gas was injected by syringe in to the test chamber. The change in sensor resistance was recorded in the presence of different concentrations of $\mathrm{NO}_{2}$ gas with the help of Keithley (6517B) electrometer interfaced with a computer. The sensing response of prepared sensor structure towards oxidizing $\left(\mathrm{NO}_{2}\right)$ gas is given as under [10]:

$$
\mathrm{S}=\frac{\mathrm{R}_{\mathrm{E}}}{\mathrm{R}_{\mathrm{a}}}
$$

where $R_{a}$ and $R_{g}$ are the values of resistance of the sensor in the presence of atmospheric air and target gas, respectively.

\section{RESULTS AND DISCUSSIONS}

Fourier transform infrared spectroscopy (FTIR) spectra were measured to investigate the SWCNTs, and the formation of the composites with $\mathrm{ZnO}$. Fig. 2 shows FTIR spectra of $\mathrm{ZnO}$, and the $\mathrm{ZnO}-\mathrm{SWCNT}(1 \mathrm{mg}), \mathrm{ZnO}$ SWCNT(3 mg) and ZnO-SWCNT(5 mg) composite samples. The two peaks at 479 and $559 \mathrm{~cm}^{-1}$ correspond to vibrational modes of the $\mathrm{ZnO}$ nanostructure [11-12]. In addition, there were two minor bands at 3425 and 1636 $\mathrm{cm}^{-1}$, which were attributed to hydrogen-bonded $\mathrm{O}-\mathrm{H}$ molecules, and are characteristic stretching modes of $\mathrm{C}$ $\mathrm{H}$ groups. These groups may have been introduced during the acid treatment, or the synthesis of the SWCNTs. The FTIR spectra, therefore, indicate that composite structures of SWCNTs and $\mathrm{ZnO}$ were successfully formed.

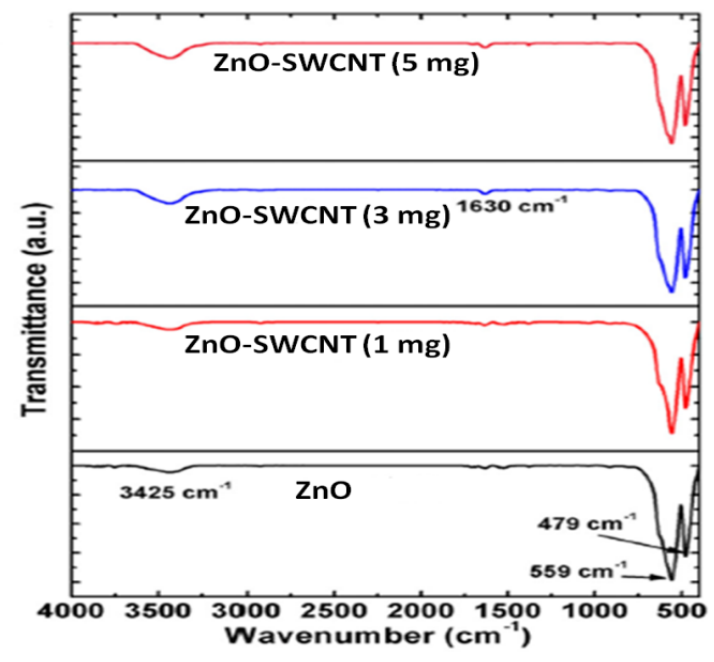

Fig. 2: FTIR spectra of $\mathrm{ZnO}, \mathrm{ZnO}-\mathrm{SWCNT}(1 \mathrm{mg}), \mathrm{ZnO}-\mathrm{SWCNT}(3$

$\mathrm{mg}$ ) and $\mathrm{ZnO}-\mathrm{SWCNT}(5 \mathrm{mg})$ composite samples.

Fig. 3 shows the FE-SEM images of SWCNT (3a), $\mathrm{ZnO}(3 \mathrm{~b})$, and the ZnO-SWCNT composite (3c). The typical morphology of $\mathrm{ZnO}$ indicates that the particle size of $\mathrm{ZnO}$ is lower than $100 \mathrm{~nm}$ with spherical morphology. The obtained morphology of the SWCNTs shows that many nanotubes are loosely entangled without any particle-like impurities. The morphology of the as 
synthesized ZnO-SWCNT composite thin film (Fig. 3c) shows that the SWCNTS are well-embedded within the matrix of the $\mathrm{ZnO}$. Film is quite porous with varying pore
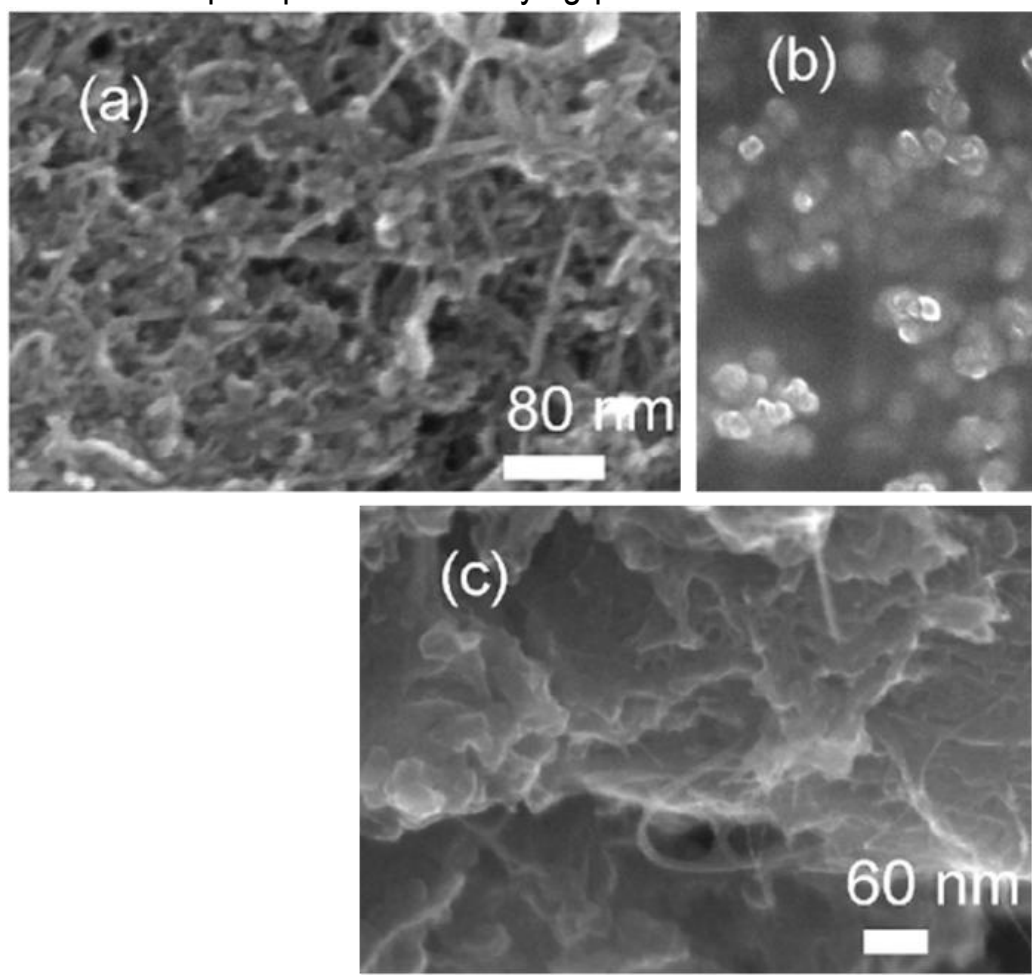

Fig. 3: FESEM image of (a) SWCNT (b) ZnO and (c) ZnO-SWCNT(5 mg) nanocomposite thin film
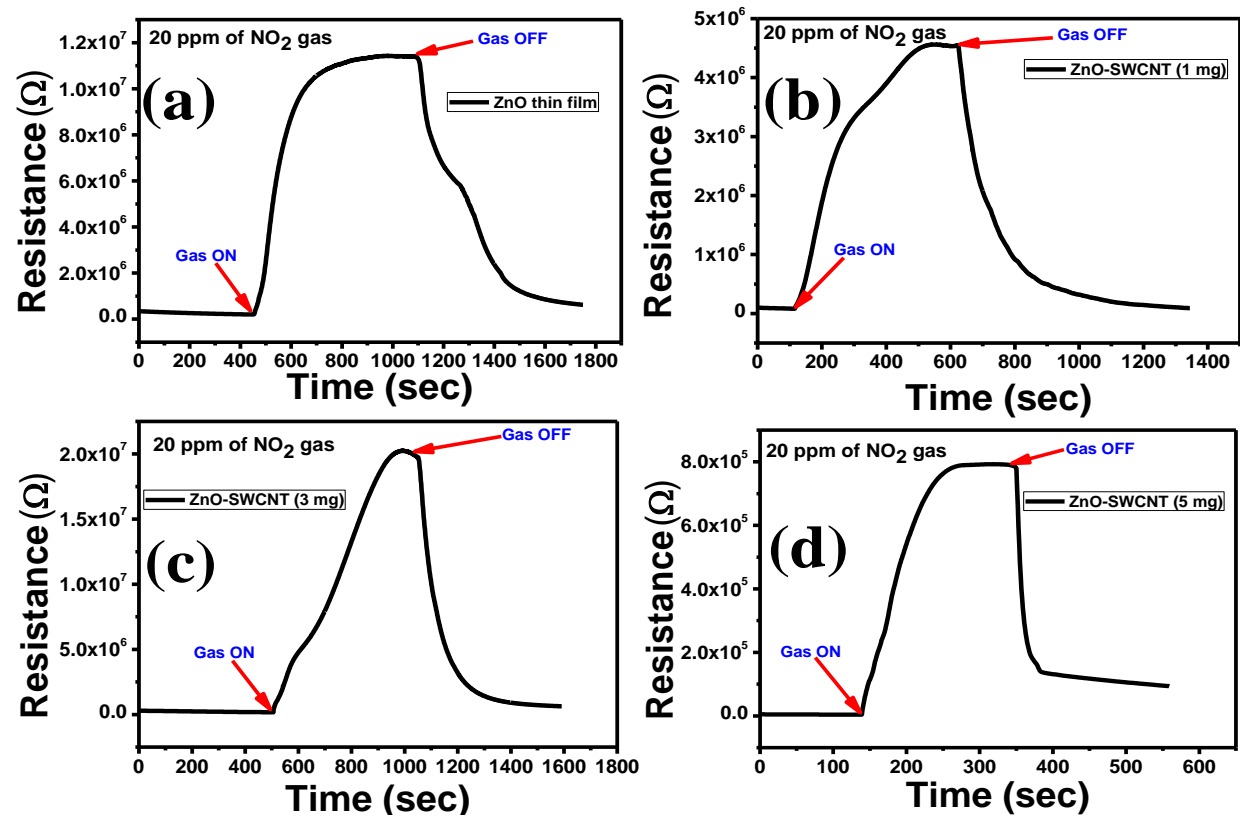

Fig. 4: Dynamic sensing characteristics of ZnO, ZnO-SWCNT(1 mg), ZnO-SWCNT(3 mg) and ZnO-SWCNT(5 mg) nanocomposite thin film at room temperature

Fig. 4 shows that the dynamic sensing characteristics of $\mathrm{ZnO}, \mathrm{ZnO}-\mathrm{SWCNT}(1 \mathrm{mg})$, ZnO-SWCNT(3 mg) and ZnO-SWCNT(5 mg) thin film at room temperature

size from $80 \mathrm{~nm}$ to $200 \mathrm{~nm}$. These pores are responsible for the adsorption of the target gases.

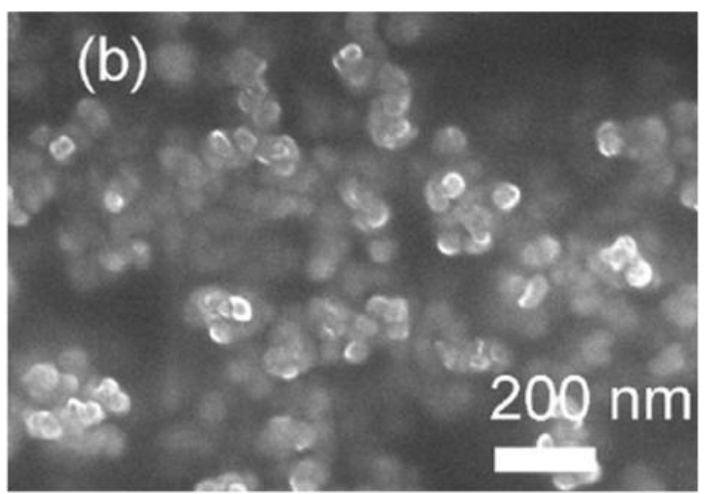


surface, results in the increase of resistance from $221 \mathrm{k} \Omega$ $\left(R_{a}\right)$ to $11.49 \mathrm{M} \Omega\left(R_{g}\right)(S=51)$. The response time and recovery times of the sensor were observed to be 8.08 and $10.66 \mathrm{~min}$, respectively at room temperature (RT) on interaction with the $20 \mathrm{ppm}$ target $\mathrm{NO}_{2}$ gas.

It can be observed from Fig. 4(b) to 4(c) that with the incorporation of SWCNT nanoparticles in $\mathrm{ZnO}$ nanoparticles colloidal solution, the sensing response has been increased to 57 to 151 at operating room temperature towards $20 \mathrm{ppm}$ of $\mathrm{NO}_{2}$ gas respectively. It can also be observed that at Fig. 4 (d) the sensor did not recover back to its initial resistance. However, it shows the quick response (tres) and recovery ( $\mathrm{t}_{\text {rec }}$ ) times as 2.45 and 1.65 min much improvement which is an improvement to previous report work [13].

The selectivity is one of the most important gas sensing properties for the gas sensors. The cross sensing response between $\mathrm{NO}_{2}$ and reducing gases such as LPG, $\mathrm{CO}_{2}, \mathrm{NH}_{3}$, and Acetone were also investigated. Fig. 5 shows the selectivity of $\mathrm{NO}_{2}$ gas to LPG, $\mathrm{CO}_{2}, \mathrm{NH}_{3}$, and Acetone in the different gas concentration for $\mathrm{ZnO}$ and $\mathrm{ZnO}-\mathrm{SWCNT}(5 \mathrm{mg})$ sensor. The maximum sensor responses $\mathrm{ZnO}-\mathrm{SWCNT}(5 \mathrm{mg})$ at room temperature (30 $\left.{ }^{\circ} \mathrm{C}\right)$ towards $\mathrm{LPG}, \mathrm{CO}_{2}, \mathrm{NH}_{3}$, and Acetone are 1.9, 1.5, 1.2 and 0.7 , respectively. It is indicated that the nanocomposite film ZnO-SWCNT(5 mg) based sensor not only has high response to $\mathrm{NO}_{2}$ but also exhibits high selectivity to reducing gas such as $\mathrm{LPG}, \mathrm{CO}_{2}, \mathrm{NH}_{3}$, and Acetone. It was found that ZnO-SWCNT(5 mg) nanocomposite thin film sensor exhibit excellent selectivity and higher sensing response with fast response and recovery time for $20 \mathrm{ppm}$ of $\mathrm{NO}_{2}$ at room temperature than $\mathrm{ZnO}$.

The sensing mechanism is based on the fact that the oxygen species were adsorbed on the surface of NCs in the air and then ionized into $O_{a d s}^{-}$or $O_{a d s}^{2-}$ by capturing the free electrons from the conduction band; there by causing decreases in conductivity. After exposure of $\mathrm{NO}_{2}$ to the zinc oxide sensing thin film, the $\mathrm{NO}_{2}$ is adsorbed on the surface of sensing film and $\mathrm{NO}_{2}$ acts as an electron acceptor in the reaction, resulting in an increase in the resistance of the sensor [14].

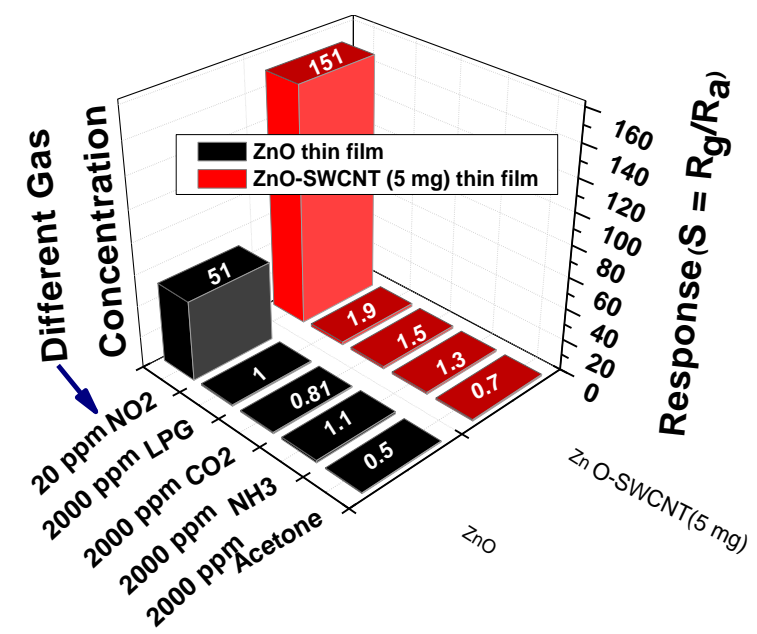

Fig. 5: Crass selectivity of $\mathrm{ZnO}$ and $\mathrm{ZnO}-\mathrm{SWCNT}(5 \mathrm{mg})$ sensor for different gas at room temperature

\section{CONCLUSION}

The ZnO thin film and ZnO-SWCNT(5 mg) nanocomposite thin film based sensors structures were designed and fabricated for detection of minimum trace level $(20 \mathrm{ppm}) \mathrm{NO}_{2}$ gas at room temperatures $\left(<40{ }^{\circ} \mathrm{C}\right)$. Sensor response was found as 151 at a room temperature. Mesoporous surface morphology having nanocrystalline grains are found to be important for obtaining enhanced sensing response characteristics.

\section{ACKNOWLEDGMENTS}

R.K. Sonker is thankful to Babasaheb Bhimrao Ambedkar University, Lucknow, U.P., India for UGC fellowship. Prof. Vinay Gupta, Department of Physics and Astrophysics, Delhi University, Delhi, India is gratefully acknowledged for providing the characterization facilities.

\section{REFERENCE}

[1] B. Wei, M. Hsu, P. Su, H. Lin, R. Wu, H. Lai, A novel $\mathrm{SnO}_{2}$ gas sensor doped with carbon nanotubes operating at room temperature, Sensors Actuators B, 101 (2004) 81-89.

[2] C. Marichy, M. Bechelany, N. Pinna, Atomic Layer Deposition of Nanostructured Materials for Energy and Environmental Applications, Advanced Materials, 24 (2012) 1017-1032.

[3] C. Marichy, N. Donato, M.-G. Willinger, M. Latino, D. Karpinsky, S.H. Yu, G. Neri, N. Pinna, Tin Dioxide Sensing Layer Grown on Tubular Nanostructures by a NonAqueous Atomic Layer Deposition Process, Adv. Funct. Mater., 21 (2011) 658-666 
[4] R.K. Sonker, B.C. Yadav, Growth mechanism of hexagonal $\mathrm{ZnO}$ nanocrystals and their sensing application, Materials Letters (2015) 160 (2015) 581-584.

[5] R.K. Sonker, B. C. Yadav, Chemical Route Deposited $\mathrm{SnO}_{2}, \mathrm{SnO}_{2}-\mathrm{Pt}$ and $\mathrm{SnO}_{2}-\mathrm{Pd}$ Thin Films for LPG Detection, Adv. Sci. Lett. 20, (2014) 1023-1027.

[6] C. Marichy, J.P. Tessonnier, M.C. Ferro, K.H. Lee, R. Schlogl, N. Pinna, M.G. Willinger, Labeling and monitoring the distribution of anchoring sites on functionalized CNTs by atomic layer deposition, J. Mater. Chem. 22 (2012) 7323-7330.

[7] J.P. Tessonnier, D. Rosenthal, F. Girgsdies, J. Amadou, D. Begin, C. Pham-Huu, D. Sheng Su and R. Schlogl, Influence of the graphitisation of hollow carbon nanofibers on their functionalisation and subsequent filling with metal nanoparticles, Chem. Commun., (2009) 7158-7160.

[8] R.K. Sonker, A. Sharma, Md. Shahabuddin, M. Tomar, V. Gupta, Low temperature sensing of $\mathrm{NO}_{2}$ gas using $\mathrm{SnO}_{2}$ ZnO nanocomposite sensor, Adv. Mat. Lett. 4 (2013) 196201.

[9] R.K. Sonker, S.R. Sabhajeet, S. Singh, B.C. Yadav, Synthesis of $\mathrm{ZnO}$ nanopetals and its application as $\mathrm{NO}_{2}$ gas sensor, Materials Letters, 152 (2015) 189-191.

[10] R.K. Sonker, A. Sharma, M. Tomar, V. Gupta, B.C. Yadav, Nanocatalyst (Pt, $\mathrm{Ag}$ and $\mathrm{CuO}$ ) Doped $\mathrm{SnO}_{2}$ Thin Film Based Sensors for Low Temperature Detection of $\mathrm{NO}_{2}$ Gas, Adv. Sci. Lett. 20 (2014)1374-1377.

[11] R.F. Silva, M.E.D. Zaniquelli, Morphology of nanometric size particulate aluminium-doped zinc oxide films, Colliod Surf Physicochem Eng-Aspect 198 (2002) 551-558.

[12] S. Sharma, S. Hussain, S. Singh, S.S. Islam, MWCNTconducting polymer composite based ammonia gas sensors: A new approach for complete recovery process, Sens. Actuators B: Chemi., 194 (2014) 213-219.

[13] A.L. Ndiaye, C. Varenne, P. Bonnet, E. Petit,L. Spinelle, J. Brunet, A. Pauly, B. Lauron, Elaboration of SWNTs-based gas sensors using dispersion techniques: Evaluating the role of the surfactant and its influence on the sensor response, Sens. Actuators B: Chemi., 162 (2012) 95-101.

[14] Ferro R, Rodríguez JA, Bertrand P, Peculiarities of nitrogen dioxide detection with sprayed undoped and indium-doped zinc oxide thin films, Thin Solid Films, 516 (2008) 22252230 . 